REFERENCE:

[1] Ez-Zaitouni, et al. AR\&T 2017;19(1):118.

Disclosure of Interest: None declared

DOI: 10.1136/annrheumdis-2018-eular.1782

\section{THU0232 IS A POSITIVE FAMILY HISTORY OF SPONDYLOARTHRITIS RELEVANT FOR DIAGNOSING AXIAL SPONDYLOARTHRITIS ONCE HLA-B27 STATUS IS KNOWN? DATA FROM THE ASAS, DESIR AND SPACE COHORTS}

M. van Lunteren ${ }^{1}$, A. Sepriano ${ }^{1,2}$, R. Landewé ${ }^{3,4}$, I.J. Berg $^{5}$, M. Dougados ${ }^{6}$, L. Gossec ${ }^{7,8}$, L. Jacobsson ${ }^{9}$, R. Ramonda ${ }^{10}$, M. Rudwaleit ${ }^{11,12}$, J. Sieper ${ }^{11,13}$, D. van der Heijde ${ }^{1}$, F.A. van Gaalen ${ }^{1} .{ }^{1}$ LUMC, Leiden, Netherlands; ${ }^{2}$ NOVA Medical School, Universidade Nova de Lisboa, Lisbon, Portugal; ${ }^{3} A R C$ Amsterdam; ${ }^{4}$ Zuyderland Hospital, Heerlen, Netherlands; ${ }^{5}$ Diakonhjemmet Hospital, Oslo, Norway; ${ }^{6}$ Paris Descartes University; ${ }^{7}$ Sorbonne Université; ${ }^{8}$ Pitié Salpêtrière Hospital, Paris, France; ${ }^{9}$ University of Gothenburg, Gothenburg, Sweden; ${ }^{10}$ University of Padova, Padova, Italy, ${ }^{11}$ Charité Campus Benjamin Franklin, Berlin; ${ }^{12}$ Klinikum Bielefeld, Bielefeld; ${ }^{13}$ German Rheumatism Research Centre, Berlin, Germany

Background: Knowledge of a positive family history (according to the ASAS definition (ASAS PFH)) for spondyloarthritis (SpA), in particular a PFH of ankylosing spondylitis (AS) or acute anterior uveitis (AAU), is considered valuable in making a diagnosis of axSpA but clusters with HLA-B27 positivity ${ }^{1}$. So a relevant clinical question is if a PFH is still important for making a diagnosis of axSpA if HLA-B27 status is known.

Objectives: To investigate in three independent axSpA cohorts if an ASAS PFH, a PFH of $A S$ or a PFH of AAU contributes to a diagnosis of axSpA in patients with known HLA-B27 status.

Methods: Baseline data of patients suspected of axSpA in the ASAS, DESIR and SPACE cohorts were analysed. In each cohort, univariable logistic regression models were performed with HLA-B27 status and ASAS PFH as determinants and a clinical axSpA diagnosis as outcome. The analyses were repeated in multivariable models with both determinants. Relative risks for axSpA diagnosis were calculated stratified on both HLA-B27 status and ASAS PFH (HLA-B27-/ASAS $\mathrm{PFH}$ - as reference). Analyses were repeated with a PFH of $\mathrm{AS}$ and a PFH of AAU. Results: In total, 1964 patients suspected of axSpA were analysed (ASAS $n=594$, DESIR $n=647$, SPACE $n=723$ ). ASAS, DESIR and SPACE patients had a mean (SD) symptom duration of 85.7 (108.4), 18.2 (10.5) and 13.3 (7.0) months; $54 \%, 47 \%$ and $38 \%$ were male; $52 \%, 58 \%$ and $44 \%$ were $\mathrm{HLA}-\mathrm{B} 27+; 44 \%, 40 \%$ and $35 \%$ had sacroiliitis on imaging (MRI and/or radiographs); $62 \%, 45 \%$ and $53 \%$ received a clinical diagnosis of axSpA; an ASAS PFH was reported in $23 \%$, $39 \%$ and $43 \%$, respectively. In the univariable analysis, HLA-B27 status was significantly associated with an axSpA diagnosis in all three cohorts; ASAS: OR 6.7 (95\%Cl 4.7-9.8), DESIR: OR 2.1 (95\%Cl 1.5-2.9), SPACE: OR 6.6 (95\% Cl 4.79.2). An ASAS PFH was univariately associated with an axSpA diagnosis in SPACE (OR $1.5(95 \% \mathrm{Cl} 1.01-2.0))$, but not in ASAS (OR $1.4(95 \% \mathrm{Cl} 0.9-2.0)$ ) and DESIR (OR $1.0(95 \% \mathrm{Cl} 0.7-1.4)$ ). In the multivariable models, HLA-B27 status was independently associated with a diagnosis of axSpA but such an independent association was not found for ASAS PFH in any cohort (ASAS: HLA-B27 OR 6.9 (95\%CI 4.7-10.2), ASAS PFH OR 0.9 (95\%CI 0.6-1.4); DESIR: HLA-B27 OR 2.1 (95\%CI 1.5-2.9), ASAS PFH OR 1.0 (95\%CI 0.7-1.3); SPACE: HLA-B27 OR $6.6(95 \% \mathrm{Cl} 4.7-9.3)$, ASAS PFH OR $1.0(95 \% \mathrm{Cl} 0.7-1.4))$. In all cohorts, the relative risk of an axSpA diagnosis was highest in HLA-B27+/ASAS PFH- patients (Abstract THU0232 - figure 1).. Similar results were found for a PFH of AS and AAU (data not shown).

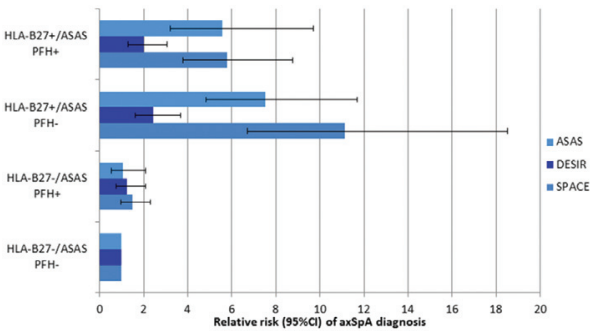

Abstract THU0232 - Figure 1. Relative risks of axSpA diagnosis in patients suspected of axSpA stratified on HLA-B27 status and a positive family history according to the current ASAS definition (ASAS PFH) per cohort. HLA-B27-/ASAS PFH- is the reference category $(\mathrm{RR}=1)$.
Conclusions: A PFH does not contribute to the likelihood of an axSpA diagnosis in back pain patients with a known HLA-B27 status. This suggests that asking for a $\mathrm{PFH}$ of $\mathrm{SpA}$ in patients presenting with back pain is redundant if HLA-B27 status is known.

\section{REFERENCE:}

[1] Ez-Zaitouni, et al. AR\&T 2017;19(1):118

Disclosure of Interest: None declared

DOI: 10.1136/annrheumdis-2018-eular.3664

\section{THU0233 SPONDYLITIS: LONG-TERM RESULTS FROM THE OUTCOME IN ANKYLOSING SPONDYLITIS INTERNATIONAL STUDY}

$\underline{\text { C. Webers }}^{1,2}$, S. Ramiro ${ }^{3}$, R. Landewé ${ }^{4,5}$, D. van der Heijde ${ }^{3}$, F. van den Bosch ${ }^{6}$, M. Dougados ${ }^{7}$, A. van Tubergen ${ }^{1,2}$, A. Boonen ${ }^{1,2} .{ }^{1}$ Rheumatology, MUMC; ${ }^{2}$ Care and Public Health Research Institute (CAPHRI), Maastricht, ${ }^{3}$ Rheumatology, LUMC, Leiden; ${ }^{4}$ Rheumatology, Amsterdam Rheumatology Center, Amsterdam;

${ }^{5}$ Rheumatology, Zuyderland Medical Center, Heerlen, Netherlands;

${ }^{6}$ Rheumatology, Ghent University Hospital and University of Ghent, Ghent, Belgium; ${ }^{7}$ Rheumatology, Paris Descartes University and Cochin Hospital, Paris, France

Background: Sick leave (SL) among patients with ankylosing spondylitis (AS) is a relevant outcome for individuals and for society. Disease related factors, contextual factors, but also SL itself may be risk factors for future adverse work outcome. To reveal predictors of SL over time, longitudinal studies are necessary. If SL itself is an independent predictor for further SL, this further underpins initiatives in clinical care to support worker participation.

Objectives: To investigate the occurrence of AS-related SL over 12 years and to explore which factors predict or explain SL.

Methods: Data from employed patients from the Outcome in Ankylosing Spondy litis International Study were used. At each visit, patients indicated the occurrence of $\mathrm{SL}$ (yes/no) in the previous inter-assessment period. Cox regressions were used to predict the hazard for a first episode of SL using baseline predictors. Generalised estimating equations (GEE) were used to investigate the association between SL and (time-lagged) predictors. To investigate whether SL predicts future SL, SL in the first year was included as covariate in a separate GEE analy sis. Due to collinearity between ASDAS, BASDAI and BASFI, separate multivariable models were computed.

Results: 139 patients (76\% males, mean [SD] age 38.7 [10.0] years) were at risk for SL during a mean (SD) period of 7.9 (3.9) years. Among the 88 patients $(63 \%)$ who ever reported SL, 62 (70\%) reported SL at more than 1 assessment. In separate multivariable Cox baseline predictors models, baseline ASDAS (HR 1.67 [95\% Cl 1.23-2.28]), BASDAI (HR 1.33 [95\% Cl 1.18-1.51]) and BASFI (HR 1.17 [95\% Cl 1.02-1.34]) were associated with increased hazard of SL, but only in male patients with a low level of education. In separate multivariable time-varying GEE models, 1 year time-lagged ASDAS (OR 1.48 [95\% Cl 1.07-2.03]), BASDAI (OR $1.31[95 \% \mathrm{Cl} 1.15-1.49])$ and BASFI (OR 1.31 [95\%Cl 1.16-1.47]) were associated with SL, but only in patients with a low level of education. Further adjustment for job type did not lead to different results, and job type itself was not significantly associated with SL. SL during the first year predicted SL over time (OR: 2.62-8.37 in different models, all $p<0.05$ ), independently of educational level, disease activ ity or physical function.

Conclusions: Disease activity and physical function predict and explain variation in SL, but only in patients with a low level of education. Prior SL results in future $\mathrm{SL}$, and SL should be considered an actionable factor for support to prevent future adverse work outcome. Research into which SL is beneficial with regard to recovery and which $\mathrm{SL}$ is a risk for work disability is needed.

Disclosure of Interest: None declared

DOI: 10.1136/annrheumdis-2018-eular.5141

\section{THU0234 BMI DOES NOT AFFECT CLINICAL OUTCOME IN PSORIATIC ARTHRITIS PATIENTS TREATED WITH} TIGHT CONTROL STRATEGY

D. Birra, G. Peluso, L. Gigante, E. De Lorenzis, G. Canestrari, G. Tanti, G. Natalello, D. Bruno, G. Ferraccioli, E. Gremese. UOC of Rheumatology, Fondazione Policlinico Universitario A. Gemelli Catholic University of the Sacred Heart, Rome, Italy

Background: Psoriatic arthritis(PsA)is characterised by several comorbidities; among these obesity and overweight have a major impact on patients' quality of 
life and on disease treatment. Obesity increases the risk of developing psoriatic arthritis in the general population compared to normal-weight subjects. Obesity increases the risk of developing arthritis in patients with psoriasis, especially for HLA B27 negative and late onset forms.

Objectives: Aim of the study was to evaluate the incidence of overweight and obesity in a cohort of PsA patients, the differences between disease phenotypes and therapeutic response between patients with normal weight and overweight/ obesity.

Methods: In this retrospective observational study 332 PsA patients, afferent to our unit between 2010 and 2017, were assessed. At each visit data on disease characteristics, BMI, ongoing treatment, joint count and clinimetric indexes were collected.

The baseline was defined as the onset of the disease in bio-naive patients or the start of the last bDMARD therapy for patients previously treated with cs or bDMARDS, while the last follow-up is considered the last visit at our unit

Results: The 332 patients had a mean age of $52.5 \pm 7.3$ years; $35 \%$ of the patients were normal weight, $39.5 \%$ were overweight and $25.5 \%$ obese. No differences were observed in terms of disease characteristics according to BMI cathegory at baseline and during follow-up, with comparable percentages of peripheral arthritis, enthesitis, dactylitis, axial arthritis or uveitis, as well as cutaneous psoriasis among the groups.

At baseline, obese patients had more tender( $4.4 \pm 5.2$ vs $2.3 \pm 3.6 \mathrm{p}=0.003)$ and swollen joints(mean value 2.3 vs $1 \mathrm{p}=0.03$ )and higher activity indexes, as for DAS28(3.3 \pm 1.2 vs $2.7 \pm 1.2 p=0.002)$ and DAPSA(15.6 \pm 9.9 vs $11.5 \pm 9 p=0.004)$ compared to normal weight patients. The same difference was observed between normal-weight and overweight patients, with higher values of DAS28(3.04 $\pm 1,4$ vs $2,7 \pm 1.2, p=0.17)$ and DAPSA(13.6 \pm 11 vs $11.5 \pm 9, \mathrm{p}=0.025)$ in overweight patients. No significant difference was observed in patients treated with NSAIDs, csDMARDs or bDMARDs according to BMI cathegory.

In 190 patients followed according to the tight control strategy, with evaluations every 3 months, the disease activity indexes after two years of follow-up became similar in obese patients compared to normal weight patients.

Among the normal-weight patients, $69.4 \%$ took csDMARDs, $48.7 \%$ were treated with bDMARDs. $74.7 \%$ of obese patients took csDMARDs, while $36.1 \%$ took bDMARDs, with no statistically significant differences between the two groups $(\mathrm{p}=\mathrm{ns})$.

In particular low-disease activity according to DAPSA was achieved in $76 \%$ of normal weight patients, compared with $68.9 \%$ of obese patients $(p=n s)$, and also the percentage of patients reaching Minimal Disease Activity in the two groups was comparable $(28.4 \%$ vs $22.7 \%, \mathrm{p}=\mathrm{ns})$.

Conclusions: Clinical manifestations of psoriatic disease do not seem to differ according to BMl cathegory:however, at the first evaluation, obese patients appear to have more disease activity than non-obese patients.

At the same treatment intensity, obese patients seem to achieve a percentage of remission comparable to normal weight patients, suggesting that the an intensive treatment strategy allows to obtain optimal results also in a more challenging group of patients.

Disclosure of Interest: None declared

DOI: 10.1136/annrheumdis-2018-eular.5502

\section{\begin{tabular}{|l|l}
\hline THU0235 & ANKYLOSING SPONDYLITIS AND RHEUMATOID
\end{tabular} ARTHRITIS HOSPITALISATION TRENDS IN THE US: DATA FROM NATIONAL INPATIENT SAMPLE}

P. Karmacharya ${ }^{1,2}$, P. Shrestha ${ }^{2}$, R. Dhital $\left.\right|^{2}$, D.R. Poudel $\left.\right|^{2} .{ }^{1}$ Rheumatology, Mayo clinic, Rochester, ${ }^{2}$ Reading Hospital and Medical Center, Reading, USA

Background: Ankylosing spondylitis (AS) imposes significant morbidity and disability in the affected population. Hospitalisation trends provide an insight as to burden of disease and long-term data is lacking. We evaluated AS related hospitalisation trends in the US from 2001-13, comparing it to the more common inflammatory arthritis- rheumatoid arthritis (RA).

Objectives: To evaluate AS related hospitalisation trends in the US in comparision to the more common inflammatory arthritis- RA

Methods: Using the Nationwide Inpatient Sample (NIS) data from 2009-2011, we identified patients $\geq 18$ years with $A S$ and RA at primary diagnosis positions based on ICD-9 codes 720.0 and $714.0,714.2,714.30-714.33$ respectively. We also excluded patients with psoriatic arthritis and inflammatory bowel disease to improve the specificity of codes used. We used the trend weight (contained in the variable TRENDWT) supplied by HCUP to study the annual trends of hospitalizations in AS and RA (2001-13). We used Stata version 13.0 (College Station, TX and Joinpoint regression analysis software to calculate yearly trends.

Results: NIS database from 2001-2013 contained 36883 (weighted count $n=175,356$ ) patients with RA and 1377 (weighted count- 6,554) patients with AS A decreasing trend in AS and RA hospitalizations was noted with an annual percentage change $(A P C)$ of 5.35 and 4.28 respectively $(p<0.05)$ (table 1 and figure 1).

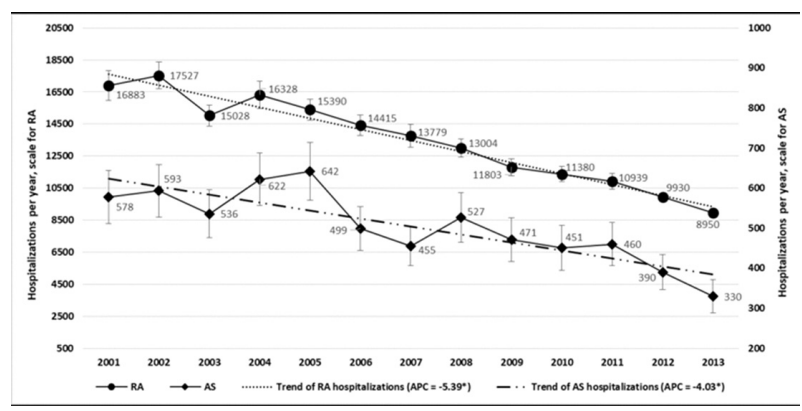

Conclusions: While recent studies have shown a rise in incidence of AS, the hospitalisation rates have declined similar to RA. Our study findings may reflect increased recognition of inflammatory back pain in the primary care setting and prompt referral and diagnosis due to improved imaging techniques of the spine and pelvis. Furthermore, the use of biologics, such as TNF and IL-6 inhibitors have significantly improved outcomes.

Disclosure of Interest: None declared

DOI: 10.1136/annrheumdis-2018-eular.5035

\section{\begin{tabular}{|l|l}
\hline THU0236 ANKYLOSING SPONDYLITIS RELATED FACTORS \\
\hline
\end{tabular} PREDICT THE PRESENCE OF CARDIAC CONDUCTION DISTURBANCES - A SWEDISH LONGITUDINAL COHORT STUDY}

K. Bengtsson ${ }^{1}$, E. Klingberg ${ }^{1}$, A. Deminger ${ }^{1}$, L.T. Jacobsson ${ }^{1}$, L. Bergfeldt ${ }^{2}$, $\mathrm{H}$. Forsblad-d'Elia ${ }^{1,3}$. $^{1}$ Department of Rheumatology and Inflammation Research ${ }^{2}$ Department of Molecular and Clinical Medicine, Institute of Medicine, Sahlgrenska Academy at University of Gothenburg, Göteborg; ${ }^{3}$ Departments of Public Health and Clinical Medicine, Rheumatology, Umeå University, Umeå, Sweden

Background: Despite a well-known association between ankylosing spondylitis (AS) and cardiac conduction disturbances (from here CCD), it's not clear which factors that predict their presence.

\begin{tabular}{|c|c|c|c|c|c|c|c|c|c|c|}
\hline Year & $R A, n$ & RA, N & $\begin{array}{c}\mathrm{SE}, \\
\mathrm{N}\end{array}$ & $\begin{array}{c}\text { RA, per } \\
1,000,000\end{array}$ & $\begin{array}{c}\text { SE, per } \\
1,000,000\end{array}$ & $A S, n$ & AS, $N$ & $\begin{array}{c}\text { SE, } \\
\mathrm{N}\end{array}$ & $\begin{array}{c}\text { AS, per } \\
1,000,000\end{array}$ & $\begin{array}{c}\text { SE, per } \\
1,000,000\end{array}$ \\
\hline 2001 & 3473 & 16883 & 927 & 564 & 29 & 120 & 578 & 66 & 19 & 2 \\
\hline 2002 & 3797 & 17527 & 842 & 579 & 26 & 131 & 593 & 66 & 20 & 2 \\
\hline 2003 & 3206 & 15028 & 648 & 490 & 18 & 115 & 536 & 60 & 18 & 2 \\
\hline 2004 & 3469 & 16328 & 853 & 527 & 26 & 133 & 622 & 66 & 20 & 2 \\
\hline 2005 & 3256 & 15390 & 646 & 497 & 18 & 132 & 642 & 72 & 21 & 2 \\
\hline 2006 & 3073 & 14415 & 631 & 456 & 17 & 106 & 499 & 54 & 16 & 2 \\
\hline 2007 & 2892 & 13779 & 713 & 437 & 20 & 95 & 455 & 49 & 14 & 2 \\
\hline 2008 & 2759 & 13004 & 574 & 406 & 15 & 112 & 527 & 62 & 16 & 2 \\
\hline 2009 & 2419 & 11803 & 517 & 373 & 14 & 97 & 471 & 55 & 15 & 2 \\
\hline 2010 & 2377 & 11380 & 471 & 363 & 14 & 93 & 451 & 56 & 14 & 2 \\
\hline 2011 & 2386 & 10939 & 488 & 348 & 13 & 99 & 460 & 54 & 15 & 2 \\
\hline 2012 & 1986 & 9930 & 223 & 323 & 7 & 78 & 390 & 44 & 13 & 1.4 \\
\hline 2013 & 1790 & 8950 & 291 & 299 & 9 & 66 & 330 & 42 & 11 & 1.4 \\
\hline TOTAL & 36883 & 175356 & & 5662 & & 1377 & 6554 & & 212 & \\
\hline APR & & $(-5.39)^{*}$ & & $(-5.35)^{\star}$ & & & $\left(\begin{array}{c}-4.03) \\
*\end{array}\right.$ & & $(-4.28)^{*}$ & \\
\hline
\end{tabular}

